\title{
Gene regulation network fitting of genes involved in the pathophysiology of fatty liver in the mice by promoter mining
}

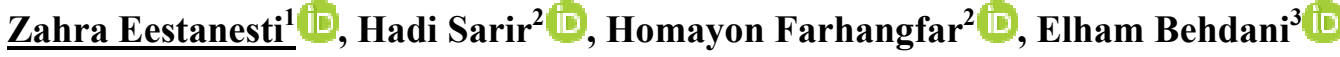 \\ ${ }^{1}$ Corresponding author; Animal Science Department, University of Birjand, Birjand, Iran \\ Tel: +9382137096 Email: estanestizahra@gmail.com \\ ${ }^{2}$ Animal Science Department, University of Birjand, Birjand, Iran \\ ${ }^{3}$ Animal Science Department, Khuzestan Agricultural and Natural Resources University, Ahvaz, Iran
}

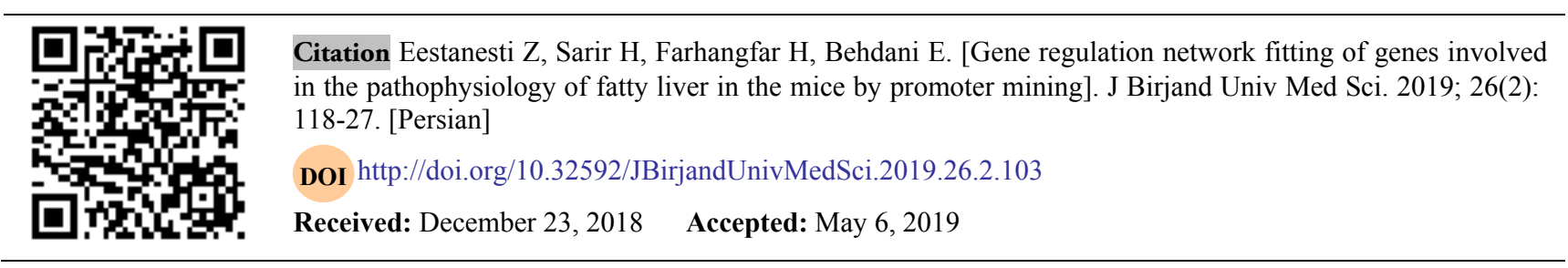

\begin{abstract}
Background and Aim: Non-Alcoholic Fatty Liver Disease (NAFLD) is the major cause of chronic liver disease in developed countries. In this study, we identified the most important transcription factors and biological mechanisms affecting the incidence of fatty liver disease using the promoter region data mining.

Materials and Methods In this study, at first, the marker genes associated with this disease were detected and the pattern of transcription factors was examined by the Genomatix software. In the whole of genome, genes with a similar binding pattern for transcription factors in the promoter region were identified as potentially effective genes on the fatty liver. By using the Cytoscape software (3.6.0), the network of transcription factors and target genes was mapped. Finally, the most important biological pathways associated with genes derived from fatty liver were studied using the DAVID database.

Results: The protein network fitting showed Creb1, Jun and Max transcription factors and Sfpi1, Ddit3 and Gsk3b genes play an important role in the development of this disease. Gene ontology analysis revealed that biological pathways including apoptosis, intracellular signals, and biosynthesis of aromatic compounds and signaling pathways of circadian rhythm, non-alcoholic fatty liver, and chemokine signals contributed to the occurrence of fatty liver disease.

Conclusion: Increasing the expression of transcription factors and genes produced can be one of the most factors affecting the onset of the disease, also, biological pathways including apoptosis, intracellular signals, and biosynthesis of aromatic compounds and signaling pathways of circadian rhythm, non-alcoholic fatty liver, and chemokine signals are important in fatty liver phenomenon.
\end{abstract}

Key Words: Promoter Analysis; Transcription Factors; Fatty Liver; Mice 


\section{برازش شبكه تنظيم ذنى ذنهاى مؤثر در پاتوفيزيولوزى كبد جرب موش بلهوسيله كاوش يروموترى}

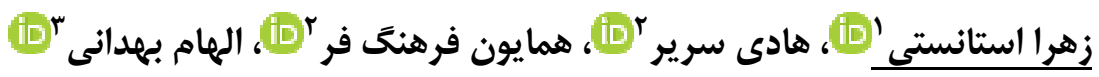

جكکبه

زمينه و هدف: بيمارى كبد هرب غيرالكلى (NAFLD)، علت اصلى بيمارى مزمن كبدى در كشورهاى توسعهيافته است. در اين

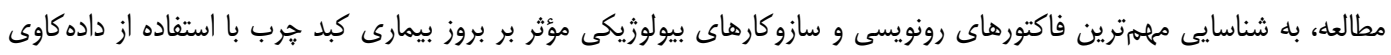
ناحيه يروموترى، يرداخته شد. روش تحقيق: در اين مطالعه، ابتدا زنهاى نشانگر مرتبط با اين بيمارى يافت شدند و الخَّى اتصال فاكتورهاى رونويسى با نرمافزار

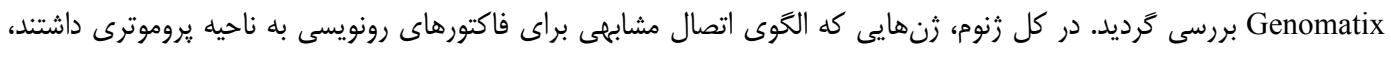

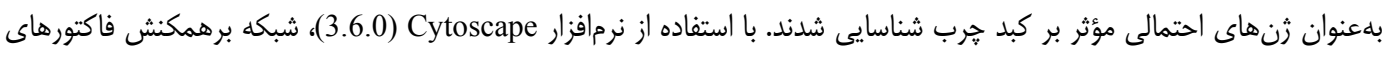

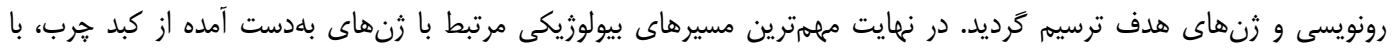

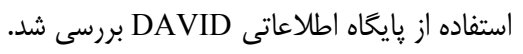

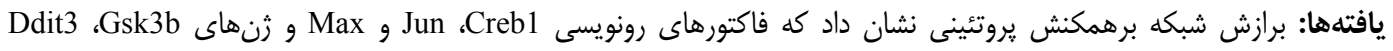

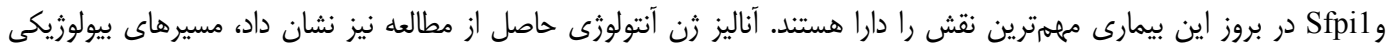

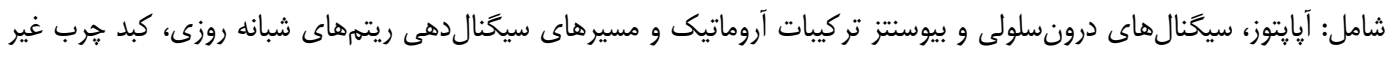

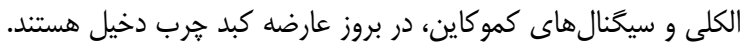

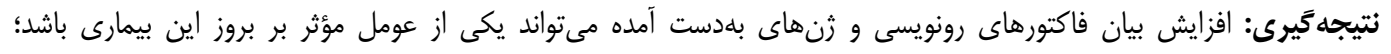

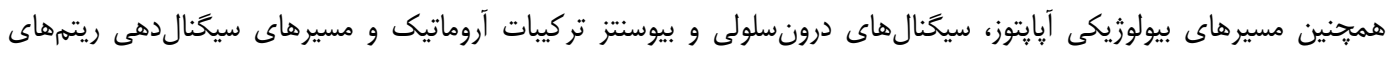

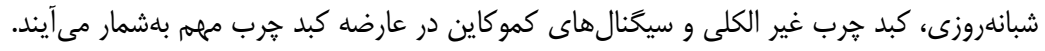
وازههاى كليدى: آناليز يروموتر؛ فاكتورهاى رونويسى؛ كبد هرب؛ موش

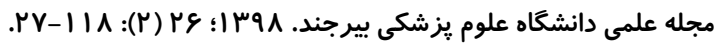

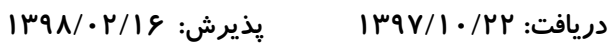

' لويسنده مسؤول؛ كَروه علوم دامى، دانشكاه بيرجند، بيرجند، ايران

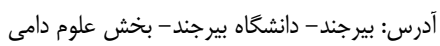
يست الكترونيكى: estanesti.zahra@gmail.com

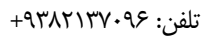

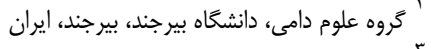

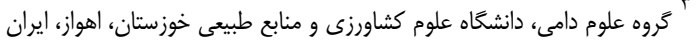




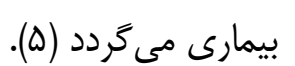

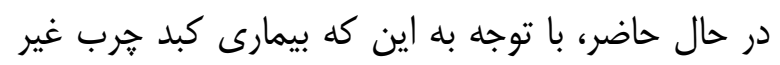

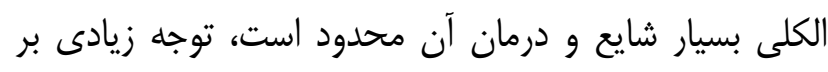

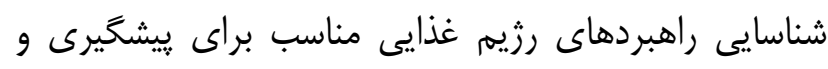

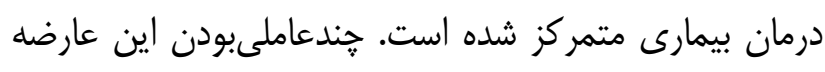

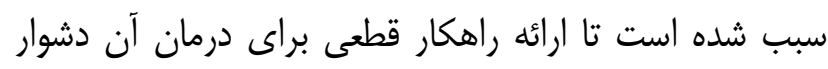

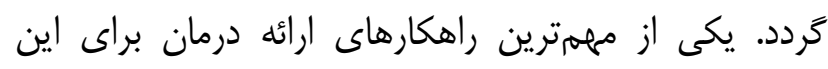

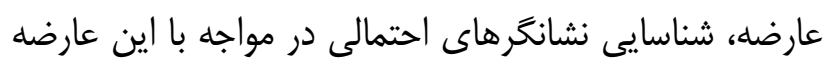

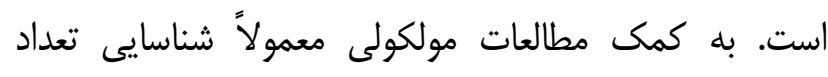

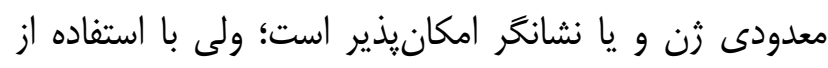

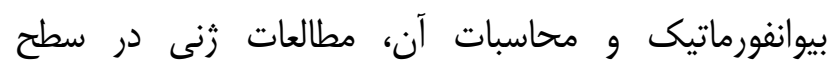

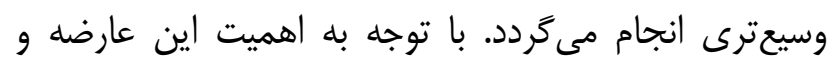

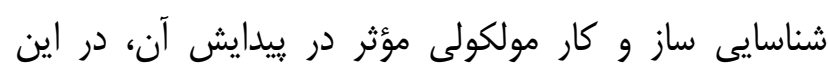

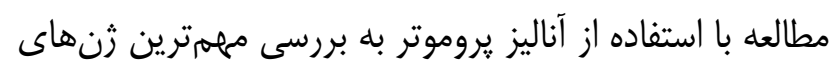

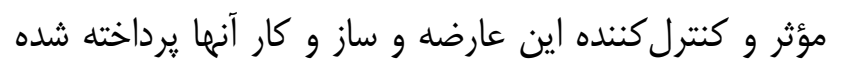

است.

روش تحقيق

\section{جستجوى زنهاى كانديد شناسايىشده در كبد جرب:}

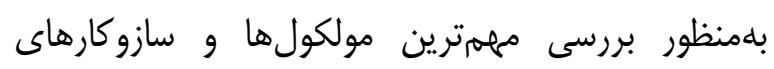

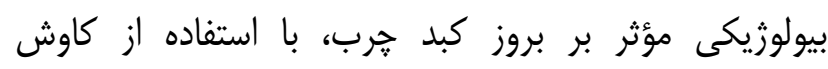

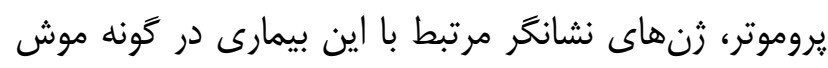

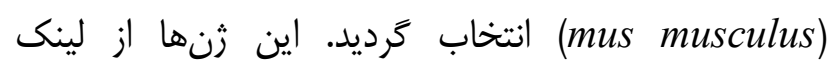

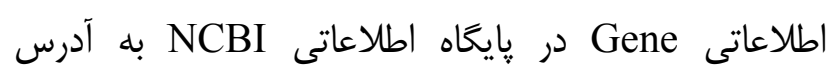
https://www.ncbi.nlm.nih.gov/gene/term شدند. در اين مرحله 19 زن بلهعنوان ثنهاى كليدى درگير در اين عارضه انتخاب گرديد (جدول ()).

\section{بررسى الكَوى اتصال فاكتورهاى رونويسى به زنهاى نشانگر عارضه كبد جرب:} الخوى اتصال يروموتر زنهاى بلهدست آمده از مرحله قبل

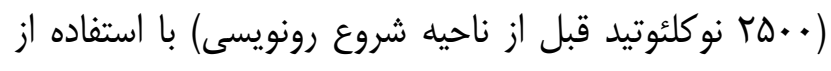

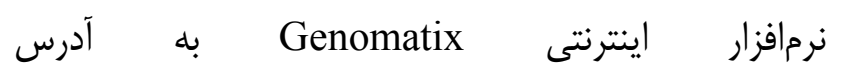

كبد، يك عضو مركزى براى كنترل متابوليك هومئوستاز

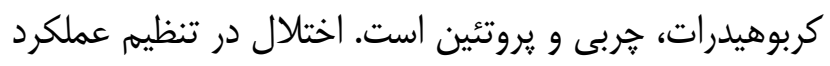
كبد مىتواند منجر به اختلالات متابوليك شود (1) (1). بيمارى كبد جرب غير الكلى (NAFLD)' بيمارىهاى مزمن كبدى است كه با تجمع ترى خليسريد در

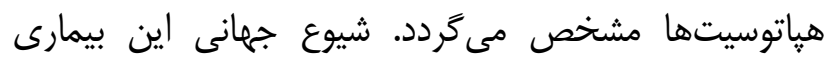

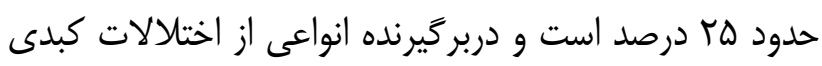

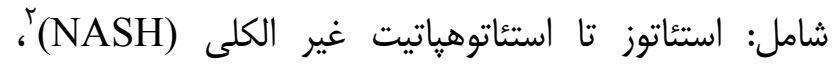

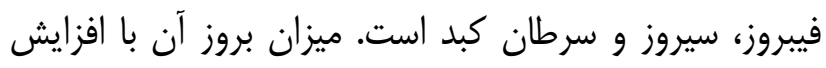
سطح جاقى، ديابت نوع دو و سندرم متابوليك افزايش مى سيابد.

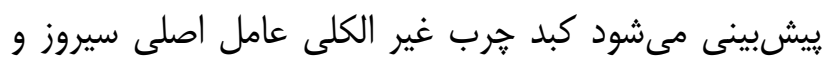

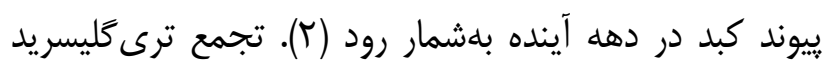

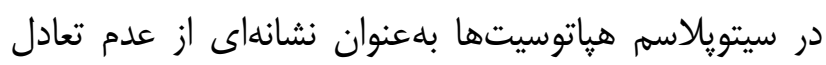

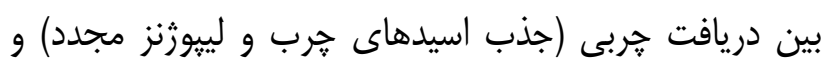

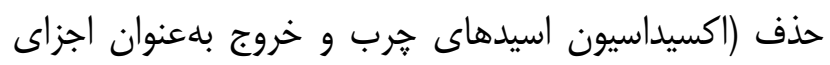

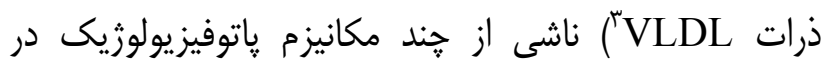
NASH

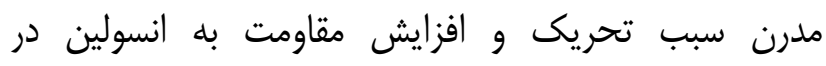
بافتهاى محيطى مىشود، و مىتواند باعث ايجاد اختلالات

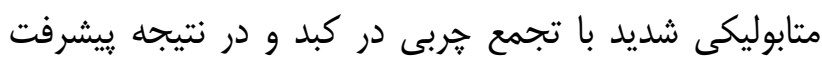

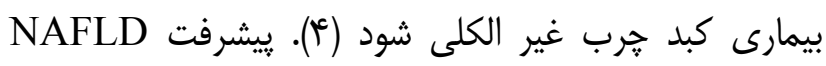
نتيجه تركيبى از عوامل زنتيكى، محيطى و متابوليكى است.

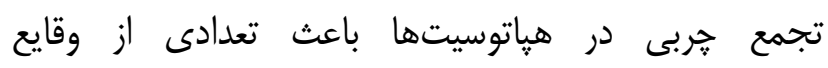

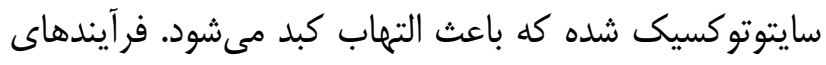
ياتولوزيكى متعددى شامل: مقاومت به انسولين، كمبود ليتين،

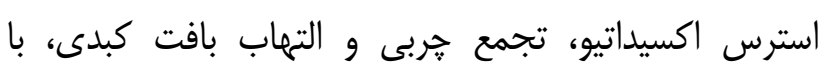

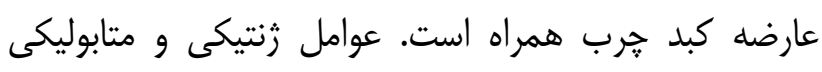

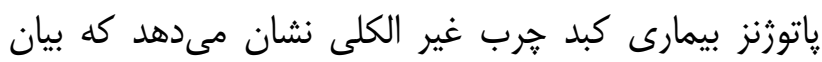

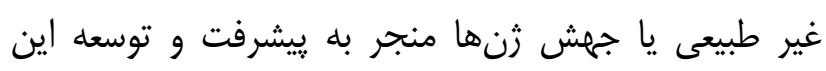

\footnotetext{
${ }^{1}$ Nonalcoholic fatty liver disease (NAFLD)

${ }^{2}$ Nonalcoholic steatohepatitis (NASH)

${ }^{3}$ Very-low-density lipoprotein(VLDL)
} 
مسيرهاى بيولوزيكى مرتبط با عارضه كبد هرب، از آناليز

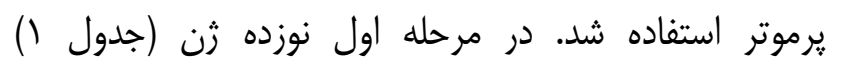

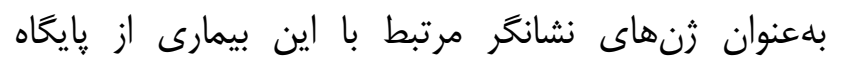
اطلاعاتى NCBI انتخاب شدند. جدول ا- زنهاى نشانكر عارضه كبد هرب در تونه موش

\begin{tabular}{ccc}
\hline Ensemble ID & $\begin{array}{c}\text { Gene } \\
\text { Symbol }\end{array}$ & Entrez ID \\
\hline ENSMUSG00000022812 & Gsk3b & 56637 \\
ENSMUSG00000037936 & Scarb1 & 20778 \\
ENSMUSG00000037411 & Serpine1 & 18787 \\
ENSMUSG00000066551 & Hmgb1 & 15289 \\
ENSMUSG00000066551 & Hmgb1 & 100862258 \\
ENSMUSG00000020538 & Srebf1 & 20787 \\
ENSMUSG00000039005 & Tlr4 & 21898 \\
ENSMUSG00000004043 & Stat5a & 20850 \\
ENSMUSG00000005952 & Trpv1 & 193034 \\
ENSMUSG00000021109 & Hif1a & 15251 \\
ENSMUSG00000020063 & Sirt1 & 93759 \\
ENSMUSG00000024401 & Tnf & 21926 \\
ENSMUSG00000037583 & Nr0b2 & 23957 \\
ENSMUSG00000026457 & Adipor1 & 72674 \\
ENSMUSG00000016194 & Hsd11b1 & 15483 \\
ENSMUSG00000020826 & Nos2 & 18126 \\
ENSMUSG00000030827 & Fgf21 & 56636 \\
ENSMUSG00000032487 & Ptgs2 & 19225 \\
ENSMUSG00000024140 & Epas1 & 13819 \\
\hline & & \\
\hline
\end{tabular}

مهمترين فاكتورهاى رونويسى متصل در ناحيه يروموترى

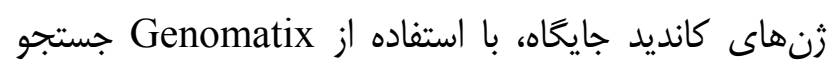

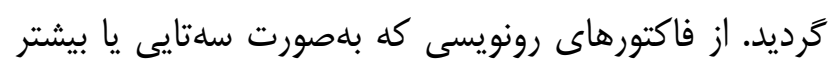

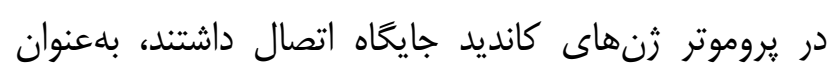

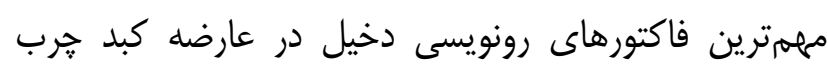

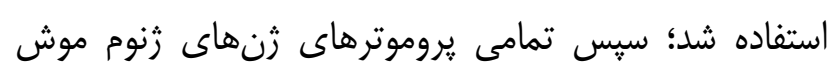

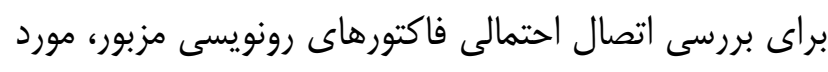

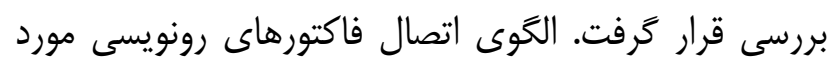

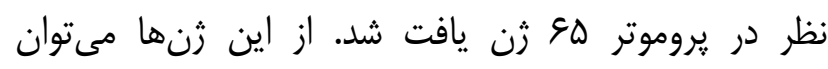

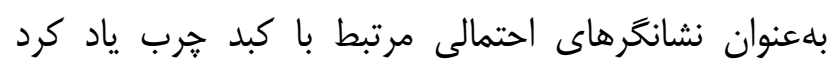

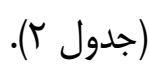

https://www.genomatix.de/solutions/genomatixsoftware-suite.html فاكتورهاى رونويسى كه بلصورت سلتايى در يروموتر تمام

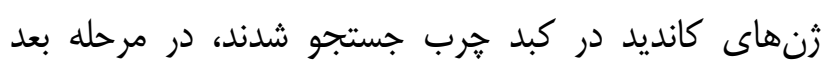

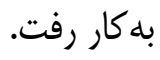

\section{دادهاوى زنوم براى شناسايى زنهاى جديد مرتبط با

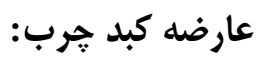
الخَوى اتصال فاكتورهاى رونويسى سلتايى بلهدست آمده از مرحله قبل بر روى يروموتر كل ثن هاى موش، با استفاده از

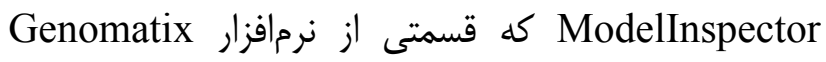
است، مورد بررسى قرار گرفت. زنهايى كه اين الخوهاى

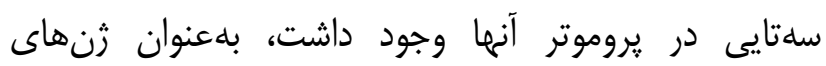

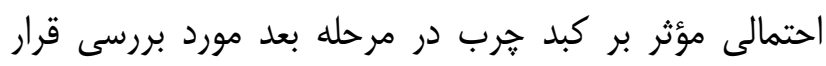
كرفتند.

\section{برازش شبكه برهمكنش يروتئينى مرتبط با عارضه كبد جرب: - جرب} با استفاده از پاييخاه داده STRING به آدرس و./رttp://string-db.org زن هاى هدف بررسى و تأييد شد. در نهايت شبكه برهمكنش

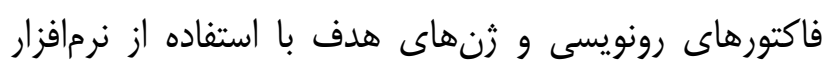
Cytoscape(3.6.0)

\section{بررسى مسيرهاى بيولوزيكى مرتبط با عارضه كبد}

زن آنتولوزى، با استفاده از زنهاى بلهدست آمده از مرحله

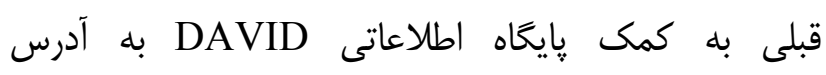
http://david.ncifcrf.gov/tools.jsp سازوكارهاى احتمالى مرتبط با كبد جرب، صورت گرفت.

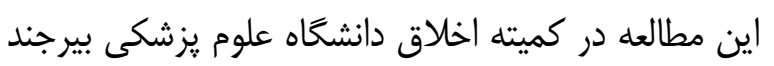
با كد Ir.bums.REC.1397.375 تصويب شده است.

يافته ها
در اين مطالعه بلمنظور شناسايى نشانكر احتمالى و 
با استفاده از پايگاه داده STRING، برهمكنش بين تعيين شدند.

نتايج حاصل از مطالعه زن آنتولوزى نشان داد كه سه سه

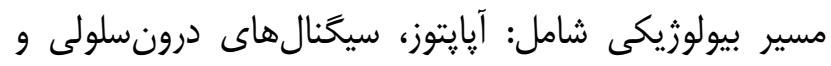

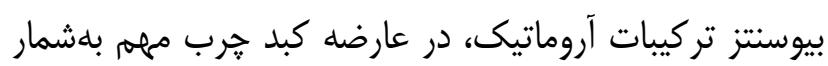

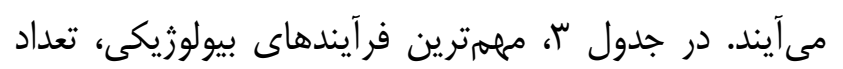

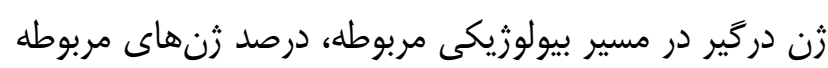
و سطح معنىدارى مسير بيولوزيكى آورده شده درئ داست.

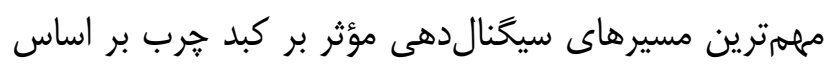

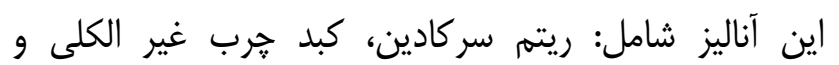

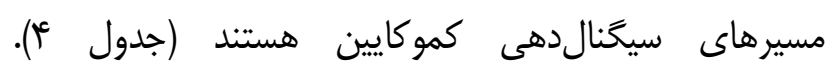

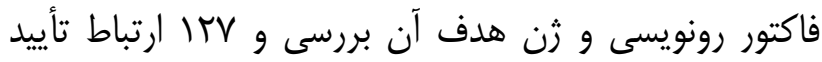

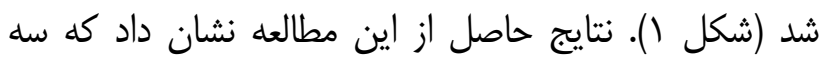

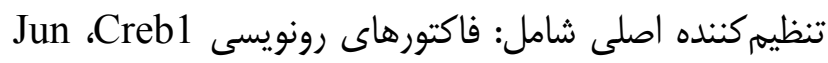
و Max (ترههاى آبى كه در تصوير بزركتر از ساير زنها

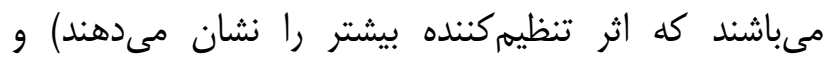

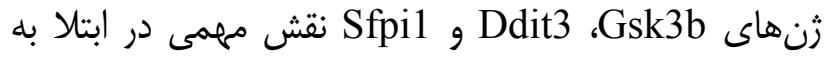
عارضه كبد هرب دارند (شكل ()). سه فاكتور رونويسى و زنهاى مزبور در اين مطالعه كه معيار انتخاب آنها ميزان ارتباط با ساير زنهاى شبكه بوده است، با داشتن بالاترين

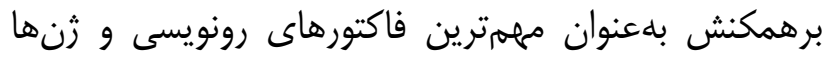

جدول ؟- زنهاى كانديد احتمالى حاصلشده از آناليز بروموتر در رابطه با عارضه كبد خرب

\begin{tabular}{|c|c|c|c|c|c|c|c|c|}
\hline \multirow{2}{*}{$\begin{array}{l}\text { Chromosome } \\
\text { Chromosome } 1\end{array}$} & \multicolumn{8}{|c|}{ Gene Symbol } \\
\hline & Npas2 & $\mathrm{Cul} 3$ & Gas5 & Inhbb & Zc3h11a & Zbed6 & Zbtb37 & \\
\hline Chromosome 10 & Ddit3 & Ctdsp2 & Btbd2 & Mbd6 & Ppp1r12a & 791309 & & \\
\hline Chromosome 11 & Trim11 & Srebfl & Csnk1d & Elp5 & Pcgf2 & Ctdnep1 & Dnah17 & 1700125H20Rik \\
\hline Chromosome 14 & Spry2 & 102631887 & Ppp3cb & Tsc22d1 & & & & \\
\hline Chromosome 15 & Adcy6 & & & & & & & \\
\hline Chromosome 16 & Gsk3b & ВC031361 & $\mathrm{Bbx}$ & Ciita & & & & \\
\hline Chromosome 17 & Epas1 & Spats1 & Bak1 & 100038605 & & & & \\
\hline Chromosome 18 & Arap3 & $\mathrm{Nr} 3 \mathrm{c} 1$ & Tcf4 & & & & & \\
\hline Chromosome 19 & Rasgrp2 & Sorcs 3 & & & & & & \\
\hline Chromosome 3 & Trim46 & Slc25a24 & Kcnd3 & Krtcap2 & & & & \\
\hline Chromosome 4 & $\operatorname{Lin} 28 \mathrm{a}$ & Esrp1 & CoI16a & Agrn & & & & \\
\hline Chromosome 5 & Wsb2 & UspL1 & Hmgb1 & & & & & \\
\hline Chromosome 6 & Zfp384 & Hoxa13 & Bhlh & & & & & \\
\hline Chromosome 7 & Fam57b & $\operatorname{Kctd} 15$ & Igf2 & Gsk3a & Erf & Maz & Numbl & \\
\hline Chromosome 9 & Prss35 & Pth $1 \mathrm{r}$ & & & & & & \\
\hline Chromosome X & Stag2 & Bcap31 & Abcd1 & & & & & \\
\hline
\end{tabular}

جدول س- مسير هاى بيولوزيكى احتمالى مر تبط با عارضه كبد جرب

\begin{tabular}{|c|c|c|c|c|}
\hline تصحيحشده P-Value & P-Value & درصد ثن & تعداد زن & مسير بيولوزيكى \\
\hline$r / \varphi \cdot E-\cdot r$ & $\mathrm{~V} / \mathrm{r} \cdot E-\cdot 9$ & $f 0 / q$ & rh & فر آيند بيوسنتز تركيبات آلى \\
\hline$r / \mathfrak{c} \cdot E-\cdot r$ & $\varphi / \mathscr{c} \cdot E-\cdot \varphi$ & $\leftarrow \Delta / q$ & ru & فر آيند بيوسنتز تركيبات آروماتيك \\
\hline $1 / V \cdot E-\cdot r$ & $r / V \cdot E-\cdot \Delta$ & 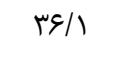 & tr & ياسخ به مواد آلى \\
\hline $1 / 9 \cdot E-\cdot \Gamma$ & $\mathbb{E} / \mathcal{C} \cdot E-\cdot \Delta$ & $18 / \kappa^{c}$ & 1. & تنظيم مرى برنامهريزىشده سلول \\
\hline $1 / 9 \cdot E-\cdot r$ & $r / l \cdot E-\cdot \Delta$ & $19 /\left.\right|^{c}$ & 1. & تنظيم فر آيند آيإيتوز \\
\hline$T / \Lambda \cdot E-\cdot \Gamma$ & $\Delta / \Lambda \cdot E-\bullet \Delta$ & $N / T$ & $\Delta$ & تنظيم مثبت فرآيند آيايتوز \\
\hline
\end{tabular}


جدول f - مسيرهاى سيگنال دهى مؤثر بر بروز كبد جرب

\begin{tabular}{|c|c|}
\hline P-Value & مسيرهاى سيخَنال دهى \\
\hline$\Delta / 1 \cdot E-\cdot \Gamma$ & ريتههاى شبانهروزى \\
\hline $1 / V \cdot E-\cdot r$ & بيمارى كبد جرب غير الكلى(NAFLD) \\
\hline 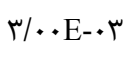 & سيخنال هاى كموكاين \\
\hline
\end{tabular}

$\cdot(1 \cdot)$

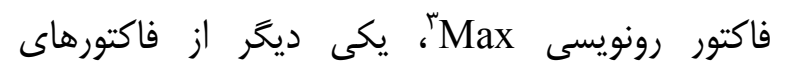

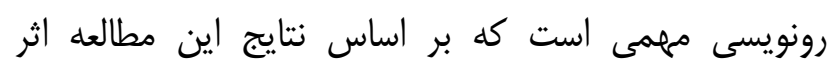

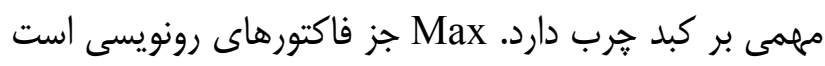

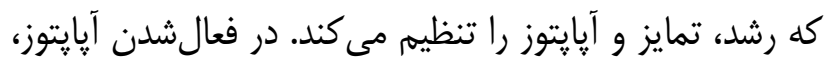

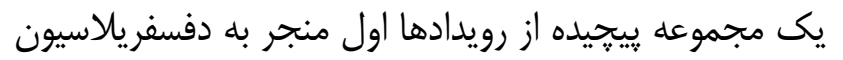

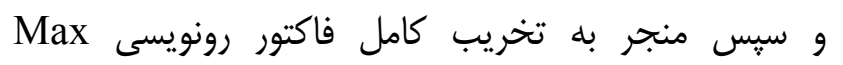
مىشود (11). مهمترين زنهاى مؤثر بر كبد هرب بر اساس شبكه زن

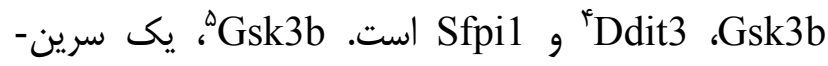
ترئونين كيناز است و نقش مهمى را در كنترل تمايز، مهاجرت

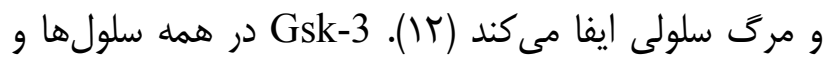

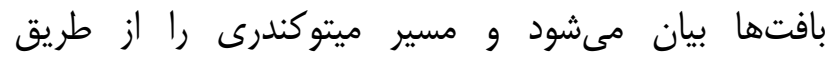

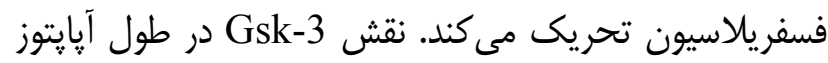

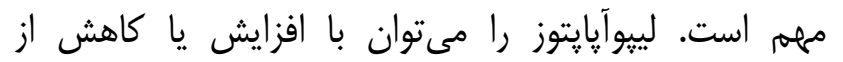

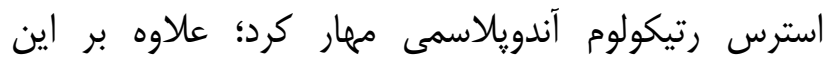
Gsk-3 فعالشدن JNK از Jsk-3 موجب آسيب شديد كبدى

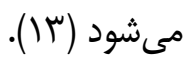

زن من Ddit3، تنظيم كننده كليدى ياسخهاى استرسى است.

افزايش بيان Ddit3 سبب توقف جرخه سلولى و در برخى از

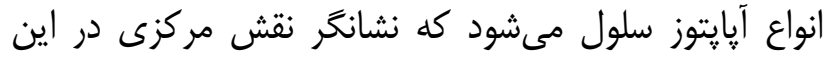

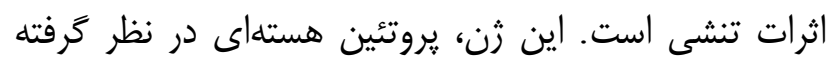

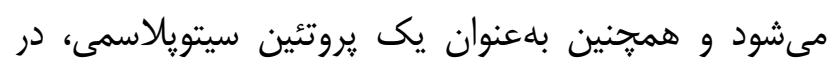

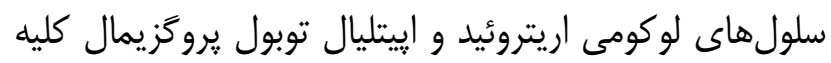

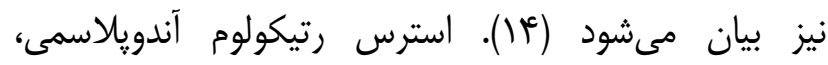

\footnotetext{
${ }^{3}$ MYC-associated factor X

${ }^{4}$ DNA damage induced transcript 3

5 glycogen synthase kinase 3 beta

שr
}

بر اساس شبكه برهمكنش تنظيم زنى، يكى از مهمترين

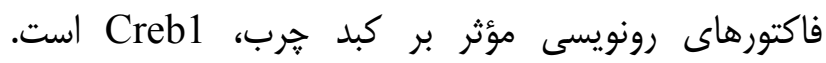

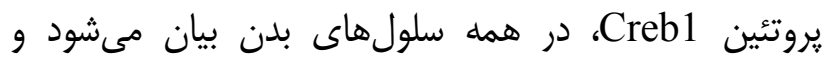

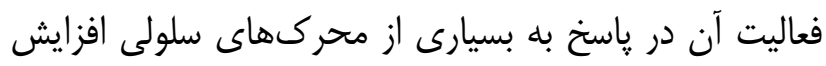

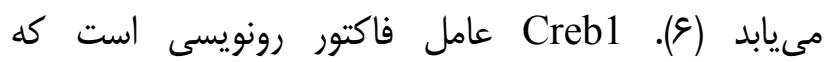

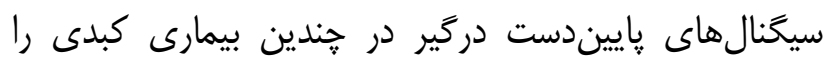

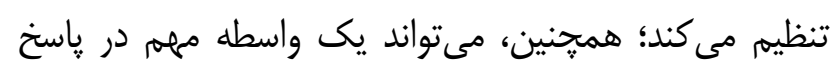

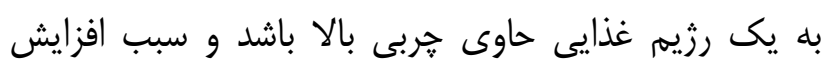

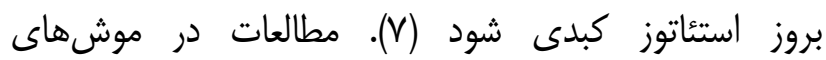

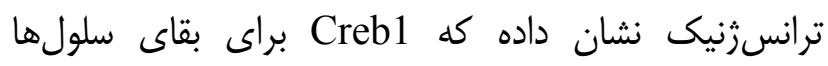

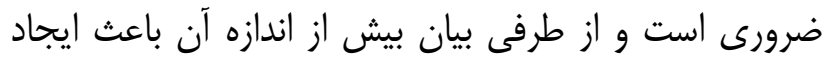

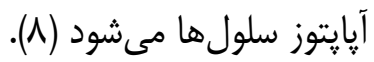

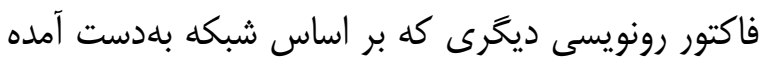

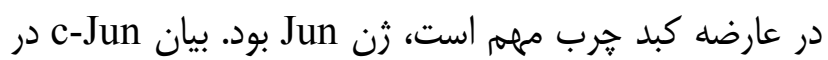

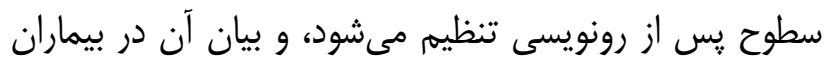

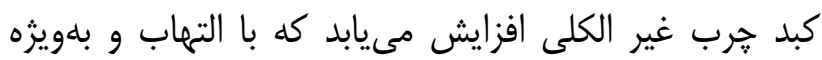

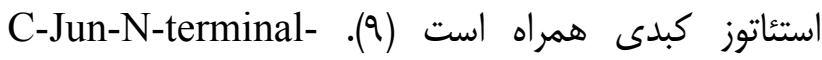
نقش مهمى در ياسخهاى پاتوفيزيولوزيك كبدى

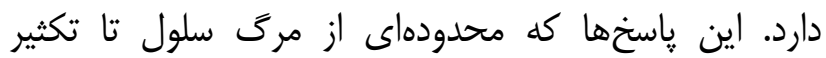
سلولى و ايجاد سرطان و همجنين متابوليسم و بقا را در برمى

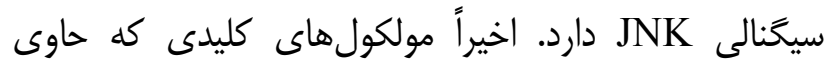

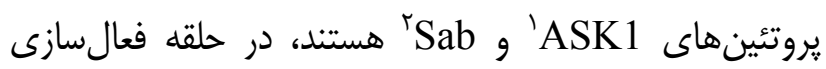
هناسايى شده كه در بروز بيمارىهاى كبدى دخيل

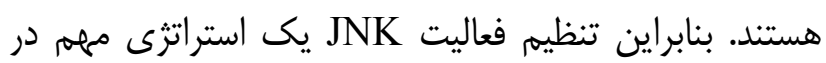

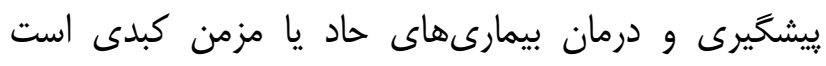

\footnotetext{
1 apoptosis signal-regulating kinase 1

${ }^{2}$ SH3-domain binding protein 5 (Sab)
} 


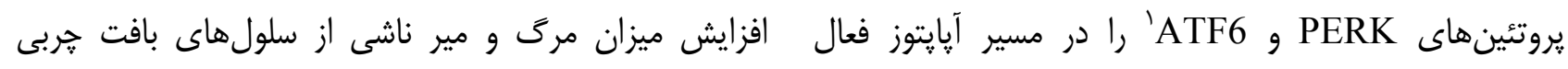

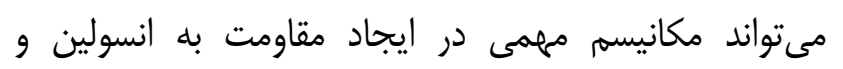

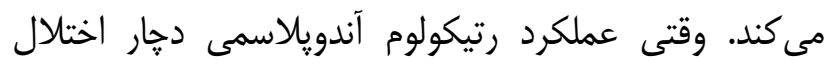
استئاتوز كبدى باشد (19).

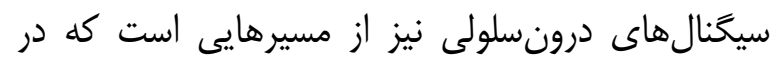

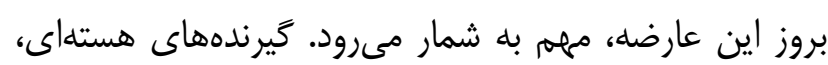

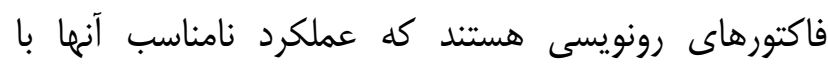

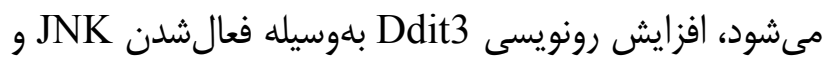

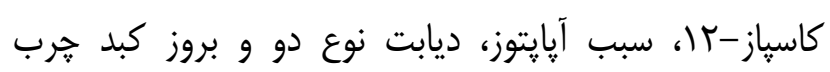

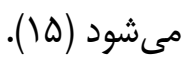
مرتبط مىباشد. يكى از اين گيرندهها مAFLD

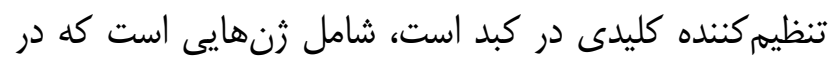

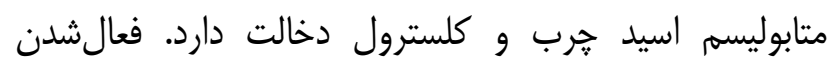
LXR سبب افزايش جاقى و استئاتوز مىشود (· (؟).

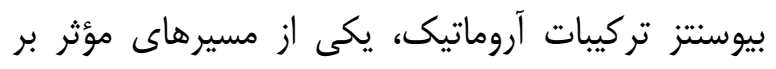
بروز اين بيمارى است. قرارگرفتن در معرض اين تركيبات

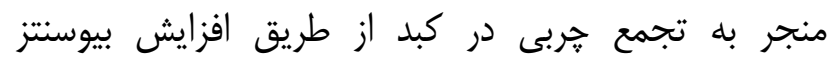

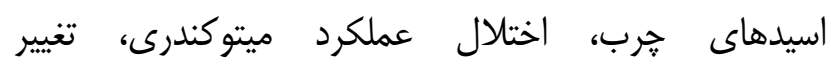

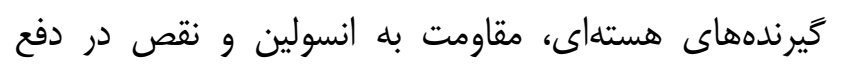

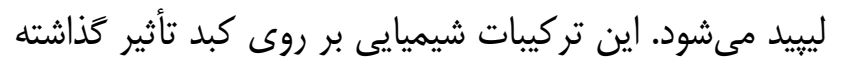

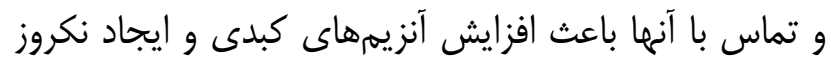

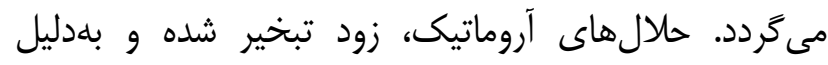

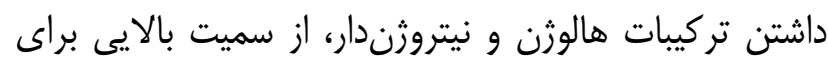

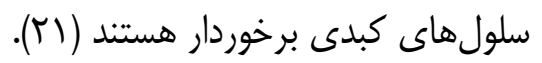

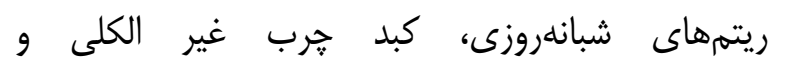
سيخنال هاى كموكاين از مسيرهاى سيخنال دهى مؤثر بر بروز

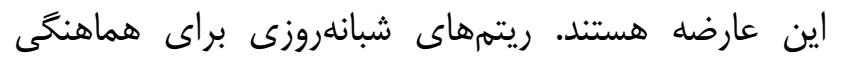

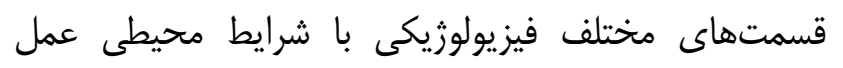

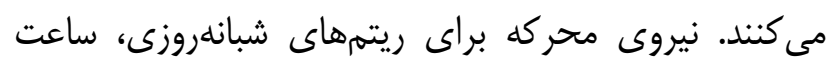

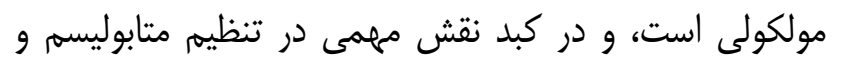

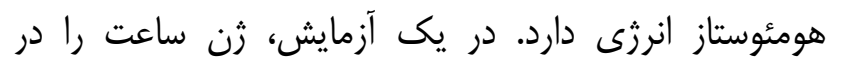

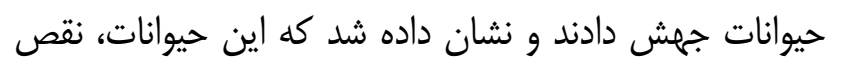

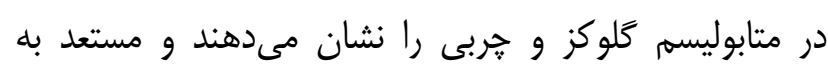

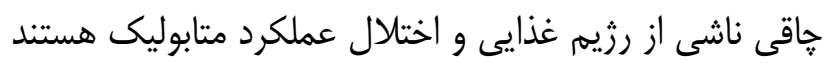

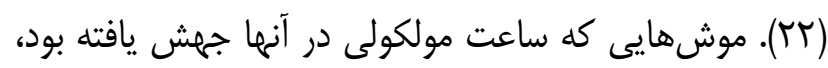

${ }^{5}$ liver X receptor

ثن Sfpi1 همجنين PU.1 نيز ناميده مىشود. PU.1

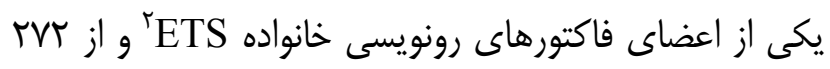

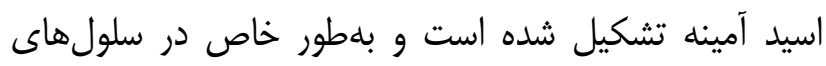

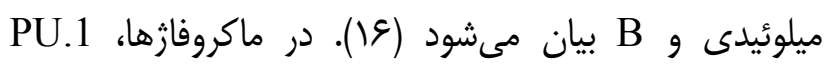

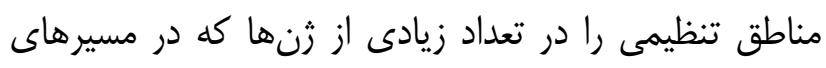

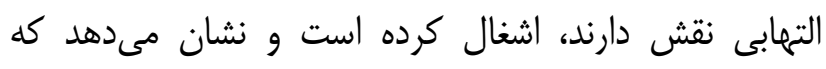

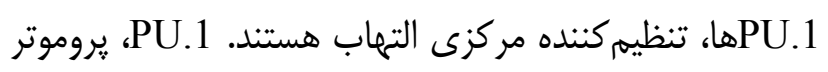

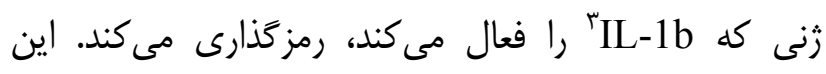
سايتوكايين، يك واسطه مركزى در التهاب است. علاوه بر مير جن.1 ،IL-1b

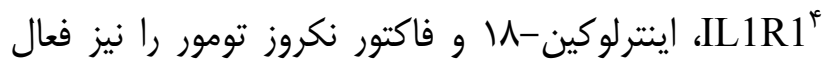

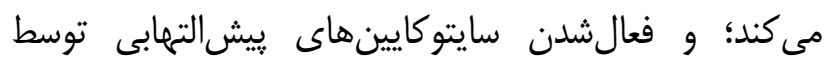

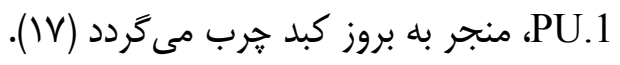

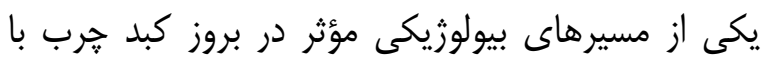

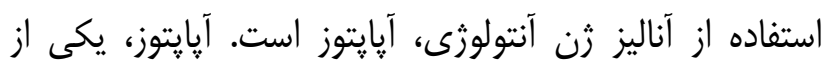

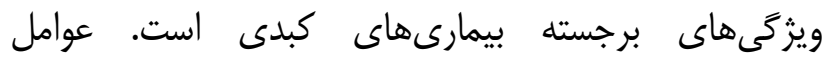
ايجادكننده مانند: الكل، اسيدهاى صفراوى سمى سمى، اسيدهاى

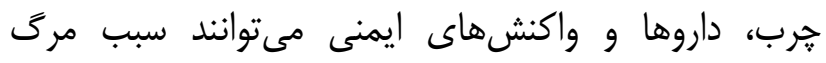

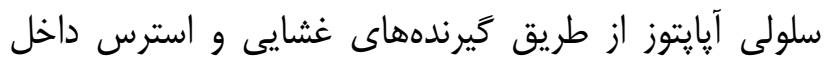

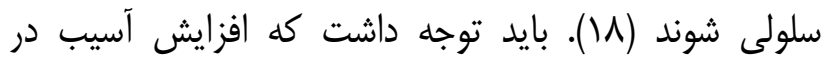
مرگ سلولى در كبد و همجنين بافتهاى محيطى بله بلعنوان

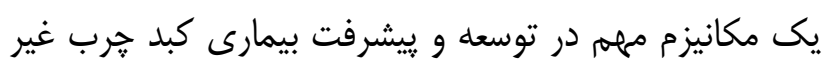
الكلى است. افزايش مرگ سلولهاى هياتوسيت توسط آيايتوز معمولاً در بيماران مبتلا به NAFLD است؛ در مر حالى كلى

\footnotetext{
1 Activating transcription factor 6

${ }^{2}$ E26 transformation-specific

3 Interleukin 1 beta

${ }^{4}$ Interleukin 1 receptor-like 1
} 
نشان دادند كه بلطور قابل توجهى محتواى ترى

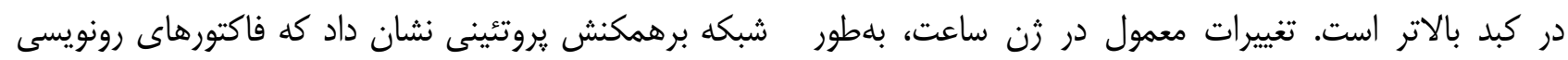

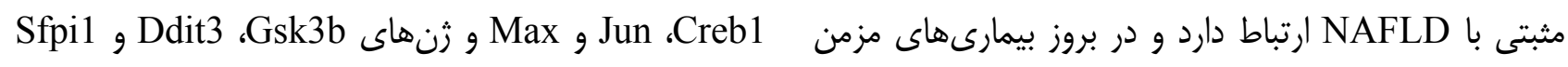

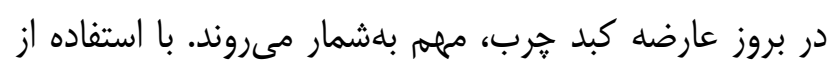

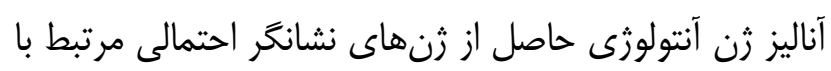
اين عارضه، نشان داده شد كه مسيرهاى بيولوزيكى شامل:

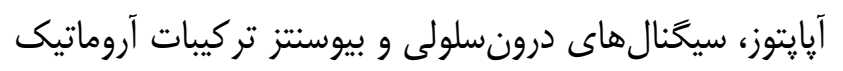

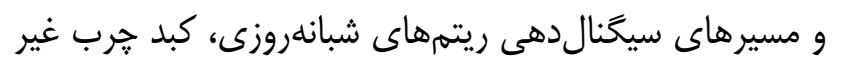

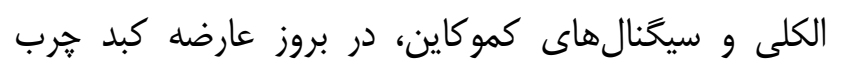
نقش دارند.

\section{تقدير و تشكر}

بدينوسيله نويسندكان مقاله از معاونت محترم يزوهشى و و

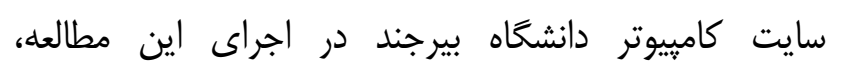
صميمانه سياس گزارى مى نمايند.

\section{تضاد منافع \\ نويسندًان مقاله اعلام مىدارند كه هيجَّونه تضاد

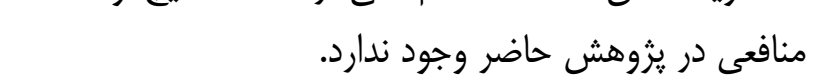 \\ در اين مطالعه با استفاده از كاوش ناحيه يروموترى،

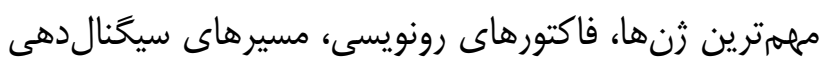 \\ منابع:}

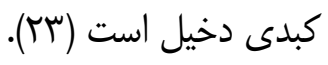
يكى از مهمترين مسيرهاى سيخنالدهى بر اساس آنس آناليز زن آنتولوزى، كموكاينها هستند. كموكاينها، يروتئين هاى

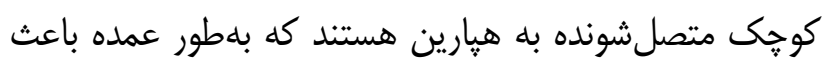

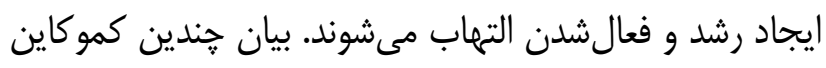

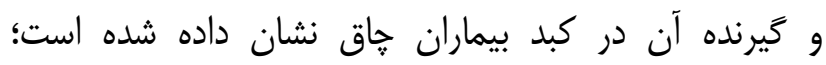

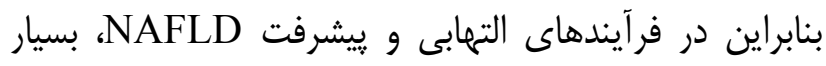
مهم هستند (זب). كموكاينها نقش كليدى در توسعه التهاب

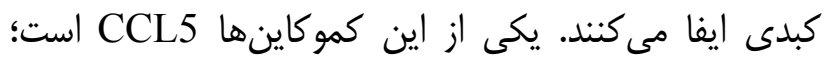

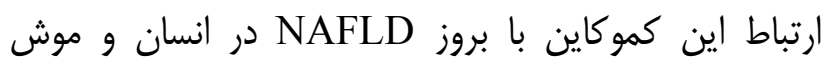
نشان داده شده است. در واقع دو مطالعه نشان دادند كان كهو جاقى، بيان كبدى CCL5 را در مدلهاى موش

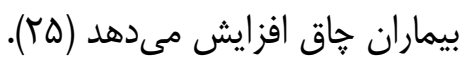

1- Stojsavljević S, Palčić MG, Jukić LV, Duvnjak LS, Duvnjak M. Adipokines and proinflammatory cytokines, the key mediators in the pathogenesis of nonalcoholic fatty liver disease. World J of Gastroenterol. 2014; 20(48): 18070-91. doi: $10.3748 /$ wjg.v20.i48.18070

2- Maurice J, Manousou P. Non-alcoholic fatty liver disease. Clin Med (Lond). 2018; 18(3): 245-50. doi: 10.7861/clinmedicine.18-3-245.

3- Berlanga A, Guiu-Jurado E, Porras JA, Auguet T. Molecular pathways in non-alcoholic fatty liver disease. Clin Exp Gastroenterol. 2014; 7: 221-39. doi: 10.2147/CEG.S62831.

4- Koo SH. Nonalcoholic fatty liver disease: molecular mechanisms for the hepatic steatosis. Clin Mol Hepatol. 2013; 19(3): 210-5. doi: 10.3350/cmh.2013.19.3.210.

5- Li L, Liu H, Hu X, Huang Y, Wang Y, He Y, et al. Identification of key genes in non-alcoholic fatty liver disease progression based on bioinformatics analysis. Mol Med Rep. 2018; 17(6): 7708-20. doi: 10.3892/mmr.2018.8852.

6- Shi Y, Venkataraman SL, Dodson GE, Mabb AM, LeBlanc S, Tibbetts RS. Direct regulation of CREB transcriptional activity by ATM in response to genotoxic stress. Proc Natl Acad Sci. 2004; 101(16): 5898-903. DOI: 10.1073/pnas.0307718101 
7- Luo WJ, Cheng TY, Wong KI, Fang Wh, Liao KM, Hsieh Y, et al. Novel therapeutic drug identification and gene correlation for fatty liver disease using high-content screening: Proof of concept. Eur J Pharm Sci. 2018; 121: 106-17. doi: 10.1016/j.ejps.2018.05.018.

8- Reynolds A, Leake D, Boese Q, Scaringe S, Marshall WS, Khvorova A. Rational siRNA design for RNA interference. Nat Biotechnol. 2004; 22(3): 326-30. DOI: 10.1038/nbt936

9- Dorn C, Engelmann JC, Saugspier M, Koch A, Hartmann A, Müller M, et al. Increased expression of c-Jun in nonalcoholic fatty liver disease. Lab Invest. 2014; 94(4): 394-408. doi: 10.1038/labinvest.2014.3.

10- Win S, Than TA, Zhang J, Oo C, Min RWM, Kaplowitz N. New insights into the role and mechanism of c-Jun-N-terminal kinase signaling in the pathobiology of liver diseases. Hepatology. 2018; 67(5): 2013-2024. doi: 10.1002/hep. 29689 .

11- Krippner-Heidenreich A, Talanian RV, Sekul R, Kraft R, Thole H, Ottleben H, et al. Targeting of the transcription factor Max during apoptosis: phosphorylation-regulated cleavage by caspase- 5 at an unusual glutamic acid residue in position P1. Biochem J. 2001; 358(Pt 3): 705-15. doi: 10.1042/0264-6021:3580705

12- Nusse R. Wnt signaling in disease and in development. Cell Res. 2005; 15(1): 28-32. DOI: 10.1038/sj.cr.7290260

13- Ibrahim SH, Akazawa Y, Cazanave SC, Bronk SF, Elmi NA, Werneburg NW, et al. Glycogen synthase kinase-3 (GSK-3) inhibition attenuates hepatocyte lipoapoptosis. J hepatol. 2011; 54(4): 765-72. doi: 10.1016/j.jhep.2010.09.039.

14- Jauhiainen A, Thomsen C, Strömbom L, Grundevik P, Andersson C, Danielsson A, et al. Distinct cytoplasmic and nuclear functions of the stress induced protein DDIT3/CHOP/GADD153. PloS one. 2012; 7(4): 33208. doi: 10.1371/journal.pone.0033208.

15- Laybutt D, Preston A, Åkerfeldt M, Kench J, Busch A, Biankin A, et al. Endoplasmic reticulum stress contributes to beta cell apoptosis in type 2 diabetes. Diabetologia. 2007; 50(4): 752-763. DOI: 10.1007/s00125-006-0590-Z

16- Iwasaki H, Somoza C, Shigematsu H, Duprez EA, Iwasaki-Arai J, Mizuno S, et al. Distinctive and indispensable roles of PU. 1 in maintenance of hematopoietic stem cells and their differentiation. Blood. 2005; 106(5): 1590-600. DOI: 10.1182/blood-2005-03-0860

17- Turkistany SA, DeKoter RP. The transcription factor PU. 1 is a critical regulator of cellular communication in the immune system. Arch Immunol Ther Exp (Warsz). 2011; 59(6): 431-40. doi: 10.1007/s00005-011-0147-9.

18- Wang K. Molecular mechanisms of hepatic apoptosis. Cell Death Dis. 2014; 5(1): e996. doi: 10.1038/cddis.2013.499

19- Alkhouri N, Carter-Kent C, Feldstein AE. Apoptosis in nonalcoholic fatty liver disease: diagnostic and therapeutic implications. Expert Rev Gastroenterol Hepatol. 2011; 5(2): 201-12. doi: 10.1586/egh.11.6.

20- Cave MC, Clair HB, Hardesty JE, Falkner KC, Feng W, Clark BJ, et al. Nuclear receptors and nonalcoholic fatty liver disease. Biochim Biophys Acta. 2016; 1859(9): 1083-99. doi: 10.1016/j.bbagrm.2016.03.002.

21- Organic solvents and related compounds. In: Lundberg I, Hogstedt Ch, Lidén C, Nise G. Textbook of Clinical Occupational and Environmental Medicine. 2nd ed. Elsevier; 2005. pp: 991-1009.

22- Kripke DF, Nievergelt CM, Joo E, Shekhtman T, Kelsoe JR. Circadian polymorphisms associated with affective disorders. J Circadian Rhythms. 2009; 7: 2. doi: 10.1186/1740-3391-7-2.

23- Tong X, Yin L. Circadian rhythms in liver physiology and liver diseases. Compr Physiol. 2013; 3(2): 917-40. doi: 10.1002/cphy.c120017.

24- Braunersreuther V, Viviani GL, Mach F, Montecucco F. Role of cytokines and chemokines in non-alcoholic fatty liver disease. World J Gastroenterol. 2012; 18(8): 727-35. doi: 10.3748/wjg.v18.i8.727.

25- Marra F, Tacke F. Roles for Chemokines in Liver Disease. Gastroenterology. 2014; 147(3): 577-94. e1. doi: 10.1053/j.gastro.2014.06.043. 


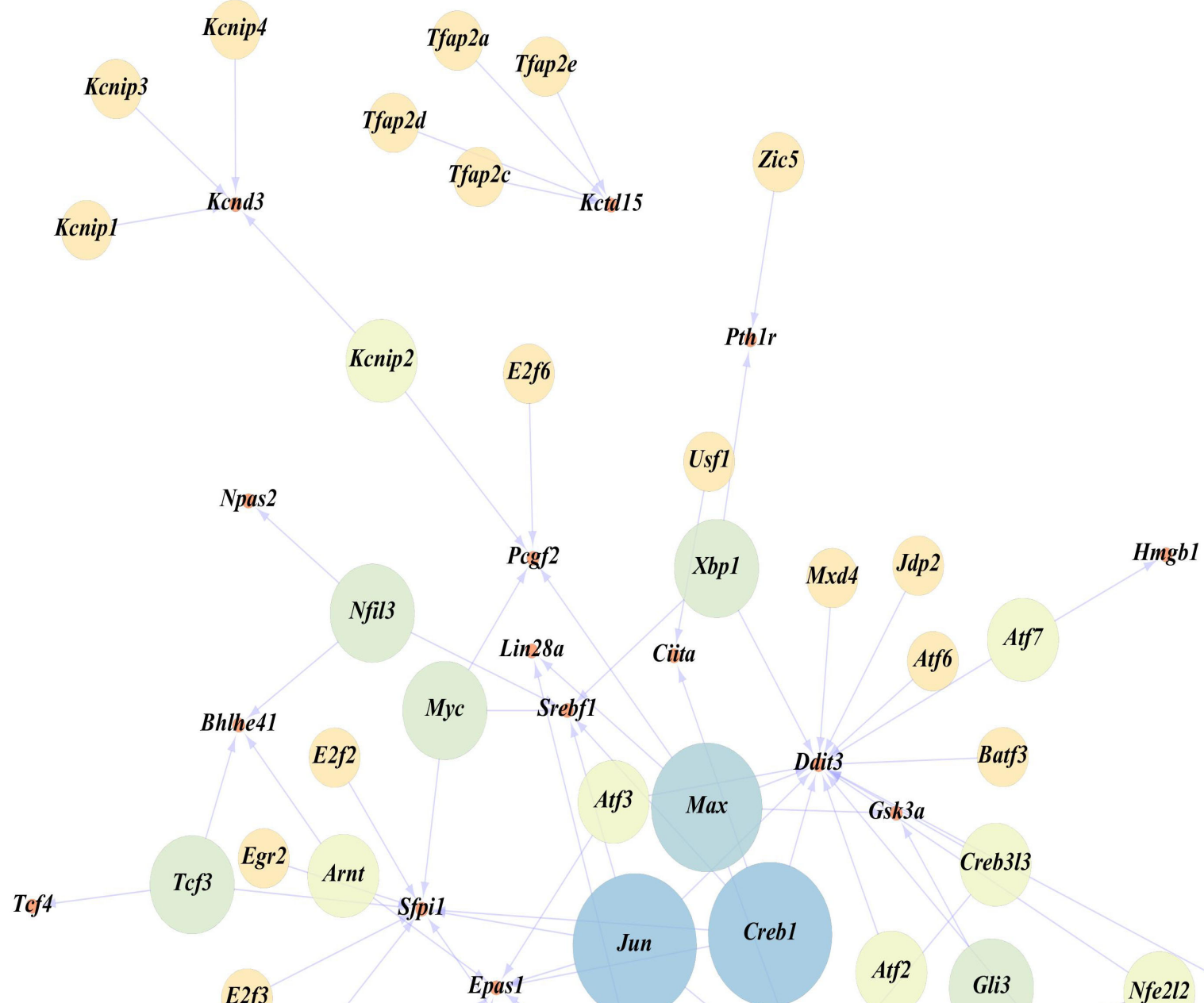

E2f3

Epas1

Gli3

Nfe2l2

Tfdp2

E2f1

Esrrb

Bak1 Gsk3b

Gli1 Csnk1d

Atf4

Crem

Ets1 Inhbb

Usf2 Gli2

Creb3

Creb5

Egr1 Creb3l2 Mycn

$\begin{array}{lllll} & \text { Spry2 } & \text { Creb3ll } & \text { Creb3l4 } & \\ & & & \text { Etv } 4\end{array}$

Igf2

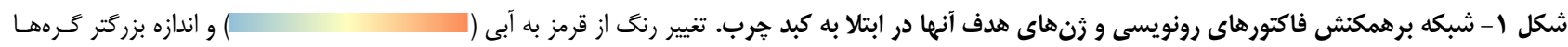
نشاندهنده تنظيم كنندگى بيشتر آنهاست. 